\title{
MANIFESTO: FRENTE DE LIBERTAÇÃO DO FAZENDEIRO IRADO
}

\section{MANIFESTO: THE MAD FARMER LIBERATION FRONT}

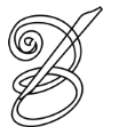 \\ Autor: \\ Wendell Berry \\ Traduzido por: \\ Yuri Amaury Pires MOLINARI ${ }^{i^{*}}$ \\ Universidade Federal do Paraná \\ Curitiba, Paraná, Brasil
}

\begin{abstract}
Resumo: Wendell Berry nasceu em 1934 em Henry County, Kentucky (EUA), onde mora com sua família em uma fazenda. É poeta, romancista, ensaísta, crítico cultural, ativista e fazendeiro; no começo dos anos 1960, foi professor universitário. Seu trabalho literário explora fundamentalmente a relação entre sujeito e lugar em um contexto rural - tema presente também em seus ensaios e em seu trabalho de ativismo. Já recebeu numerosos prêmios por sua obra. Sua poesia une traços da écloga e da poesia didática, sem abdicar de aspectos políticos. O poema que ora apresentamos em tradução - "Manifesto: the mad farmer liberation front", do livro The Country of Marriage (1973) - exemplifica bem a veia política de Berry, calcada em uma peculiar ironia e uma dicção direta, assim como o universo rural de onde emanam as personagens, cenários e problemáticas exploradas pelo poeta.
\end{abstract}

Palavras-chave: Tradução. Poesia estadunidense. Poesia contemporânea. Wendell Berry.

Abstract: Wendell Berry was born in 1934 in Henry County, Kentucky (USA), where he lives with his family on a farm. He is a poet, novelist, essayist, cultural critic, activist and farmer; in the early 1960s, he was a university professor. His literary work fundamentally explores the relationship between subject and place in a rural context - a theme also presents in his essays and in his activism. He was the recipient of numerous awards for his work. His poetry blends traces of the eclogue and didactic poetry, whilst maintaining political aspects. The poem we now present in translation - "Manifesto: the mad farmer liberation front", from the book The Country of Marriage (1973) - exemplifies Berry's political vein, based on a peculiar irony and a direct diction, as well as the universe from where emanate the characters, scenarios and problems explored by the poet.

Keywords: Translation. American poetry. Contemporary poetry. Wendell Berry.

RECEBIDO EM: 22 de outubro de 2019

ACEITO EM: 17 de fevereiro de 2020

PUBLICADO EM: março 2020 

alvez seja o caráter múltiplo de Wendell Berry, abrangendo vários aspectos de sua vida e obra, que o torne um escritor difícil de apresentar. Nascido em 1934 em Henry County, Kentucky (EUA), frequenta a Universidade do Kentucky em Lexington, onde obtém bacharelado (1956) e, em seguida, mestrado (1957) em Letras - Inglês. Ao receber a Wallace Stegner Fellowship em 1958, estuda no programa de Escrita Criativa da Universidade Stanford, na Califórnia, junto a escritores como Edward Abbey e Ken Kesey. Berry passa o ano de 1961 na Toscana, financiado por uma Guggenheim Fellowship, e retorna aos EUA para lecionar na Universidade de Nova Iorque, de 1962 a 1964, e na Universidade do Kentucky, de 1964 a 1977. Nos dez anos seguintes, Berry concentra-se em sua carreira literária e em seu cargo de editor na Rodale Press, assim como no trabalho na fazenda adquirida em 1965 (onde mora até hoje com sua família). Volta a lecionar na Universidade do Kentucky em 1987, abandonando a carreira universitária em 1993.

Essa multiplicidade geográfica que dominou os trinta primeiros anos da vida de Wendell Berry - contrastando com o firme enraizamento territorial e cultural que caracteriza sua instalação definitiva na área rural de sua terra natal - soma-se a uma multiplicidade profissional: 240 além de escritor (agraciado com numerosos prêmios estadunidenses, como o Vachel Lindsay Prize from Poetry, a National Humanities Medal e o Ivan Sandrof Litefime Achievement Award), Berry é fazendeiro e ativista. Como seria de se esperar, essas três ocupações distintas acabam interligando-se de um modo muito natural. Dessa forma, em sua extensa prática de ativismo político e ambiental, Berry envolve-se também em questões concernentes à agricultura (principalmente os direitos dos pequenos fazendeiros e a oposição ao agronegócio), e se manifesta por meio de ensaios e artigos críticos que já chegaram a ser publicados no jornal The New York Times. Suas coletâneas de ensaios costumam girar em torno de temas da ecologia e da responsabilidade humana - esta última, intimamente relacionada ao seu cristianismo pacifista.

Enquanto fazendeiro adepto de métodos semi-arcaicos (em oposição à agricultura mecanizada), Berry incentiva a produção orgânica e local, e escreveu para revistas especializadas nessa área. Finalmente, no âmbito literário (já que também sua atividade de escrita é múltipla e, além dos gêneros de não-ficção, recobre gêneros ficcionais: poesia, romance e conto), é possível observar uma influência profunda e persistente das suas outras duas ocupações: não apenas o universo rural se encontra materializado nas personagens, espaços e reflexões da obra de Berry, como as inquietações políticas do autor acabam destiladas de maneira direta ou indireta nos enredos e problemáticas abordados. 
Não são raras as comparações de sua obra romanesca com a de William Faulkner, uma vez que as histórias de seus oito romances se passam em Port Williams, um lugarejo fictício baseado em Port Royal e análogo ao Yoknapatawpha County de Faulkner (embora situado no Kentucky, e não no Mississippi). Focalizando, cada um, o ponto de vista de um habitante distinto da cidade, os romances de Berry costuram dramas humanos ao contexto socio-histórico das mudanças nas práticas agrícolas e do declínio da sociedade agrária tradicional, e ensejam reflexões sobre o significado (literal e metafórico) do casamento - que o autor encara como um laço de fidelidade e responsabilidade entre indivíduos, famílias, comunidades e o lugar em que elas se encontram.

Em seus mais de trinta livros de poesia, desenvolve-se uma espécie de écloga contemporânea da terra cultivada, inserida em uma tradição geórgica cristã (GARRARD, 2006, p. 161) - o que de forma alguma implica proselitismo religioso. Com uma lírica simples e direta que retoma uma dicção wordsworthiana, o casamento do humano com o mundo natural por meio do trabalho e dos afetos é celebrado. Os ciclos naturais, o trabalho braçal, a vida animal e vegetal da fazenda, as relações familiares e comunitárias - a vida simples, em suma, ocupa os versos de Berry. Porém, a mesma pulsão didática que reconhece na vida rural a beleza de um modo de existência mais responsável e significativo também aponta as feridas deixadas pela agressão de um sistema de produção pós-industrial e de uma ideologia de mercado exploratória e belicista. Nesse sentido, muitos poemas do autor apresentam um tom melancólico ou de denúncia; e é aí, nesse terreno que se configura como ponto de tangência entre o locus amoenus bucólico e a civilização tecnocrática contemporânea, que reside a demonstração mais palpável do inconformismo ativista e combativo de Berry. Pois, se ele se permite lamentar as perdas históricas humanas e ambientais e os rumos sui- e eco-cidas da humanidade, esse lamento nunca é resignado; e ele desemboca, invariavelmente, na resistência - obstinada, intransigente, irônica e apaixonada.

O poema que apresentamos em tradução ${ }^{i i}$ (parte de um projeto em curso, que pretende traduzir uma antologia da poesia de Berry) sintetiza, a nosso ver, os principais aspectos da lírica berryana. Sob a égide da insurgência política, o Fazendeiro Irado (provável alter ego de Berry) obscurece os traços trágicos da realidade denunciada, privilegiando um discurso irônico e franco no primeiro quinto do poema. O tom muda quase bruscamente a partir do décimo segundo verso, dando lugar a uma série de injunções arrebatadas (e arrebatadoras) que constituem simultaneamente uma profissão de fé e um guia didático para uma boa vida - que, talvez justamente por ser boa, também é uma vida de oposição desobediente. 
Love the quick profit, the annual raise, vacation with pay. Want more of everything ready-made. Be afraid to know your neighbors and to die. And you will have a window in your head. Not even your future will be a mystery any more. Your mind will be punched in a card and shut away in a little drawer. When they want you to buy something they will call you. When they want you to die for profit they will let you know. So, friends, every day do something that won't compute. Love the Lord. Love the world. Work for nothing. Take all that you have and be poor. Love someone who does not deserve it.

242 Denounce the government and embrace the flag. Hope to live in that free republic for which it stands.

Give your approval to all you cannot understand. Praise ignorance, for what man has not encountered he has not destroyed. Ask the questions that have no answers. Invest in the millennium. Plant sequoias. Say that your main crop is the forest that you did not plant, that you will not live to harvest. Say that the leaves are harvested when they have rotted into the mold. Call that profit. Prophesy such returns. Put your faith in the two inches of humus that will build under the trees every thousand years.

Listen to carrion -- put your ear close, and hear the faint chattering
Ame o lucro fácil, o aumento anual, férias remuneradas. Queira mais de tudo pré-fabricado. Tenha medo de conhecer os vizinhos e de morrer. E terá uma janela na sua cabeça. Nem mesmo seu futuro será um mistério, não mais. Sua mente será perfurada em um cartão e fechada em uma gavetinha.

Quando quiserem que compre alguma coisa eles vão te chamar. Quando quiserem que morra pelo lucro vão te avisar.

Então, amigos, todo dia façam algo que não seja computado. Amem o Senhor. Amem o mundo. Trabalhem sem receber. Peguem tudo que têm e sejam pobres. Amem alguém que não merece.

Denunciem o governo e abracem a bandeira. Queiram viver na livre república que ela representa.

Aprovem toda coisa que não puderem entender. Aplaudam a ignorância, pois o que o homem não encontrou, ele não destruiu. Façam as perguntas que não têm resposta. Invistam no milênio. Plantem sequoias. Digam que suas safras são de florestas que vocês não plantaram, que vocês não vão colher em vida. Falem que as folhas são colhidas quando apodrecem em fungos.

Digam que é lucro. Profetizem esse rendimento. Coloquem sua fé nos dois dedos de húmus que crescem sob as árvores a cada mil anos.

Escutem as carcaças - aproximem suas orelhas, e ouçam o vago rumor 
of the songs that are to come.

Expect the end of the world. Laugh.

Laughter is immeasurable. Be joyful

though you have considered all the facts.

So long as women do not go cheap

for power, please women more than men.

Ask yourself: Will this satisfy

a woman satisfied to bear a child?

Will this disturb the sleep

of a woman near to giving birth?

Go with your love to the fields.

Lie down in the shade. Rest your head

in her lap. Swear allegiance

to what is nighest your thoughts.

As soon as the generals and the politicos can predict the motions of your mind,

lose it. Leave it as a sign

to mark the false trail, the way

you didn't go.

Be like the fox

who makes more tracks than necessary,

some in the wrong direction.

Practice resurrection. de canções que estão por vir.

Esperem o fim do mundo. Riam.

A risada é incomensurável. Sejam alegres

apesar de terem considerado todos os fatos.

Enquanto mulheres não se venderem pelo

poder, agradem mulheres mais que homens.

Perguntem-se: isto contentaria

uma mulher contente em ter um filho?

Isto perturbaria o sono

de uma mulher perto do parto?

Vão com seus amores aos campos.

Deitem-se na sombra. Pousem a cabeça

no colo dela. Jurem fidelidade

ao que margeia seus pensamentos.

Assim que os generais e políticos

puderem prever as inclinações da sua mente,

larguem-na. Deixem-na como sinal

que marca a trilha falsa, o caminho

que vocês não tomaram.

Sejam como a raposa

que deixa mais rastros que o necessário,

alguns errando a direção.

Pratiquem ressurreição.

\section{REFERÊNCIA}

BERRY, Wendell. The Country of Marriage. New York: Harcourt, Brace \& World, 1973.

GARRARD, Greg. Ecocrítica. Brasília: Editora UnB, 2006.

\footnotetext{
i* Yuri Amaury Pires MOLINARI - Letras - Português e Inglês (2015) pela Universidade Tecnológica Federal do Paraná. Mestre (2019) e Doutorando em Letras pela/na Universidade Federal do Paraná. Universidade Federal do Paraná, Setor de Humanidades, Letras e Artes, Programa de Pós-Graduação em Letras. Curitiba, Paraná, Brasil. Currículo acadêmico: http://lattes.cnpq.br/5103350900020877

ORCID: https://orcid.org/0000-0001-6905-7433

E-mail: yuri_amaury@yahoo.com.br

ii Autorização para uso do original e para publicação de tradução sem fins comerciais em periódico acadêmico foi obtida pelo tradutor junto à editora Counterpoint Press, mediante contrato, em 17 de janeiro de 2020.
} 